\title{
Evaluative Beliefs First
}

Forthcoming in Oxford Studies in Normative Ethics Vol. 8

\author{
Ben Bramble \\ Trinity College Dublin \\ brambleb@tcd.ie
}

\begin{abstract}
Many philosophers think that it is only because we happen to want or care about things that we think some things of value. We start off caring about things, and then project these desires onto the external world. In this chapter, I make a preliminary case for the opposite view, that it is our evaluative thinking that is prior or comes first. On this view, it is only because we think some things of value that we care about or want anything at all. This view is highly explanatory. In particular, it explains (i) the special role that pleasure and pain play in our motivational systems, (ii) why phenomenal consciousness evolved, and (iii) how the two main competing theories of normative reasons for action-i.e., objectivism and subjectivism-can be reconciled. After explaining why this is so, I respond to the most serious objections to this view, including that it cannot account for temptation and willpower, or for the existence and appropriateness of the reactive attitudes.
\end{abstract}

Keywords. Desire; evaluative belief; guise of the good; value; phenomenal consciousness; pleasure; pain; normative reasons for action; objectivism; subjectivism; willpower; weakness of will; reactive attitudes.

\section{Introduction}

What is the relationship between desire ${ }^{1}$ and evaluative belief ${ }^{2}$ ? Many philosophers think that there is no deep or special relationship between these kinds of states. Thinking something good can cause one to want it, as when, for example, thinking that a Bernie Sanders victory would be a good thing leads one to want it. Also, wanting something can cause one (via certain irrational processes) to think it good, as when, for example, a desire that Roger Federer win causes one to think that his winning would be a good thing. But this exhausts the relationship. It is entirely possible to want something without thinking it good at all-for example, for one's friend to fail. It is also possible to think something good without wanting it at all-for example, a trip to the dentist. Finally, when one both wants something and thinks it

\footnotetext{
${ }^{1}$ Desires are the springs of action. To want something is (at least, in part) to be disposed to bring it about. Without desire, there could be no motivation or free action. Even the belief that something has value or worth, or that some action is morally required, would be insufficient to motivate a being who happened to care about nothing. Moreover, desires are fundamentally for states of affairs, not objects. While we often speak of wanting particular objects - say, a coffee, a raise, a holiday, etc. - what we mean here, strictly speaking, is that we want it to be the case that we get one of these things. Finally, desires can be either intrinsic or instrumental. To want something intrinsically is to want it for its own sake. To want something instrumentally is to want it for the sake of something else. For more on the concept of desire, see Schroeder (2004).

${ }^{2}$ An evaluative belief is a belief that a particular thing is good (or has value) simpliciter. The good simpliciter is that which makes the world go better rather than worse, impersonally considered. Something can be good in some way, even if it is not good all-things-considered (or best).
} 
good, the strength of one's desire can be quite out of proportion to the degree to which one thinks it good.

Some philosophers, however, believe that there is a deep or special relationship between desire and evaluative belief. One common idea, for example, is that desire is in some sense prior or fundamental. Whenever we think something good this is only because there is something we want, and we are projecting this desire onto the external world. A second possibility is that desires and evaluative beliefs are really just one and the same kind of state, or else that evaluative beliefs are a particular kind of desire. ${ }^{3} \mathrm{~A}$ third possibility is that desires are identical, not to evaluative beliefs, but to appearances of the good. On this proposal, to desire something is for it to seem good to one. ${ }^{4}$ In the same way a straight stick in water can look bent, in wanting something, one is in a state in which this thing seems good to one, even though one might know it is not.

In this chapter, I want to make a preliminary case for a different kind of deep or special relationship between desire and evaluative belief. I will argue that it is evaluative thinking that comes first or is prior, and in some sense explains all desire. This view, Evaluative Beliefs First (EBF), involves two claims, both asserted as necessary truths:

1. Each of us has just one intrinsic desire, for the good (understood de dicto rather than de re). More precisely, the content of this desire is that things go better rather than worse.

2. Every other desire we have-i.e., every instrumental desire-is the combination of (a) this intrinsic desire for the good and (b) some belief that a certain thing (the thing desired) would be good in some way.

According to EBF, while no desire is identical to an evaluative belief, some desires (instrumental ones) are partly constituted by evaluative beliefs.

I will start off by outlining some major benefits of EBF. EBF, I will argue, allows us to explain:

i. the special role that pleasure and pain play in our motivational systems,

ii. why phenomenal consciousness evolved, and

iii. how the two main competing theories of normative reasons for actioni.e., objectivism and subjectivism - can be reconciled.

I will then respond to what I consider the most serious objections to EBF. Finally, I will explain some important implications of EBF.

\section{The Role of Pleasure and Pain}

Pleasure and pain have a special role to play in the motivational systems of all desiring creatures. Consider the following five facts:

\footnotetext{
${ }^{3}$ For some suggestions along these lines, see Humberstone (1987), McNaughton (1988), and Gregory (forthcoming)

${ }^{4}$ See especially Stampe (1987), Tenenbaum (2007), Oddie (2005).
} 
1. Pleasures and pains are the first things we humans care about.

2. Pleasures and pains are the only things most non-human animals ever come to care about. Only intelligent creatures, like us, ever come to have broader concerns.

3. It is only intelligent beings, like us, who ever cease to care about their own pleasures and pains.

4. Evolution works by selecting for creatures for whom the things conducive to survival and reproduction (e.g., sex, nutritious food, treatment of wounds, etc.) are pleasurable, and for whom the things that interfere with survival and reproduction (e.g., bodily damage) are painful. It does not work by selecting for beings who care about these things directly.

5. There is vast agreement in the desires of all desiring creatures for pleasure and avoidance of pain.

If EBF is true, we can explain these things. Why are pleasures and pains the first things we humans care about? And why is it only intelligent creatures, like us, who ever come to have broader concerns? If EBF is true, we can say it is because pleasures and pains are the most obviously good and bad things, respectively. We humans care about pleasures and pains before anything else because caring about things involves having evaluative thoughts, and the most basic evaluative truths are that pleasure is good and pain is bad. We come to care about things beyond our own pleasures and pains just when we start to recognise value in other things (say, in the well-being of others). Most non-human animals, by contrast, care only about their own pleasures and pains because caring involves having evaluative thoughts, and such animals never reach the level of sophistication in their evaluative thinking required to recognise value in other things.

If EBF is true, it is no coincidence that the first things we humans come to care about, and the only things most non-human animals ever come to care about, are also the most obviously good and bad things. It is not otherwise so easy to explain why this is so.

Now, some philosophers are reluctant to accept that non-human animals like cats, dogs, etc., are capable of thinking in evaluative terms at all. But it is important to emphasise that all I am proposing we attribute to such animals is some awareness, possibly hazy, when they are feeling some pain, that there is something awful going on here (something worth avoiding), and when they are feeling some pleasure, that there is something good going on here (something worth having or promoting). These are very basic insights, and as Irwin Goldstein says, "creatures of elementary intelligence are still capable of elementary insights". ${ }^{5}$ The idea is not, of course, that these animals can think about value, or have evaluative thoughts in anything like a human language.

Consider, next, that it is only intelligent beings, like us, who are capable of ceasing to care about their own pleasures and pains - for example, in the case of certain monks or yogis. What explains this fact? If EBF is true, we can explain it by pointing out that it is only humans who are sophisticated enough in their evaluative

${ }^{5}$ Goldstein (1980), p. 357. 
thinking to think that pleasure and pain are not of value (whether or not this thought is ultimately true). The only beings who ever come to be indifferent to their own pleasures and pains are those who, after some amount of study or ideological commitment, come to think that these feelings do not, after all, matter. On EBF, this is no coincidence. By contrast, why do cats, dogs, etc., never cease to care about their own pleasures and pains? If EBF is true, it is because they are incapable of the requisite level of sophistication in their evaluative thinking. Without EBF, there is considerable mystery here.

How does evolution work? It works by selecting for creatures for whom the things conducive to survival and reproduction (e.g., sex, nutritious food, treatment of wounds, etc.) are pleasurable, and for whom the things that interfere with survival and reproduction (e.g., bodily damage) are painful. It works, in other words, by exploiting a desire, common to all creatures, for pleasure and avoidance of pain. It does not work by selecting for creatures who want sex, nutritious food, treatment of wounds, avoidance of bodily damage, etc., directly.

If EBF is true, we can easily explain why evolution works like this. It is because it had to. There can be no beings who care intrinsically about sex, nutritious food, and so on. So, such beings were simply not available for evolution to select for. ${ }^{6}$ By contrast, if EBF is false, it is hard to explain why evolution works like this.

Consider, finally, the vast agreement or uniformity in the desires of all desiring creatures for pleasure and avoidance of pain. This agreement is itself quite striking, and calls out for an explanation, especially given how different most creatures are from each other in almost all other respects. If EBF is true, we can explain this uniformity simply by noting again the sheer obviousness of the fact that pleasure is good and pain is bad. We all agree here because we are responding to the way things are. If EBF is false, it is not so easy to explain this vast uniformity. ${ }^{7}$

\section{Why Phenomenal Consciousness Evolved}

A key question in the philosophy of mind is why phenomenal consciousness evolved. ${ }^{8}$ According to one proposed answer, it evolved just because there was an evolutionary advantage in being able to sense or detect things in one's environment (say, food, danger, how to get from $A$ to $B$, etc.). But there is a glaring problem with this answer. This is that there seems no reason why such detection should require phenomenology or an inner life, no reason why it couldn't have all gone on 'in the dark'. Many entities, after all-robots, thermostats, plants, and so on-can sense things in their environment without having any phenomenology. Why couldn't we have had the same functional properties we do but without an inner life?

\footnotetext{
${ }^{6}$ There can, on EBF, be beings who believe that sex, nutritious food, etc., are intrinsically good, and so who want these things not simply as a means to pleasure or avoidance of pain. But such evaluative thinking is sufficiently sophisticated that it was unlikely to have occurred as a mutation early on in our evolutionary history.

${ }^{7}$ We cannot explain it in terms of an appeal to evolution. As I've mentioned, evolution seems to work by exploiting the universal desire for pleasure and avoidance of pain.

${ }^{8}$ Phenomenal consciousness exists just where there are mental states such that there is something 'that it is like' to be in them.
} 
If EBF is true, there is a better answer available. Consciousness evolved because (i) it was necessary for desire, and (ii) desire (specifically, desire for the things conducive to survival and reproduction) was fitness-enhancing. Why was consciousness necessary for desire? It is because

A. desire requires evaluative thought,

B. the "cheapest" (or perhaps only) way for creatures to acquire evaluative concepts-and so to start thinking in evaluative terms-was by encountering things of value, and

C. pleasures and pains are the most obviously good and bad things (and might even be necessary conditions of value in the universe).

Consciousness was selected for, in other words, not for its ability to help us detect things in and navigate our environment, but for the value it made possible, and so (due to the truth of EBF) for the desiring it allowed. It was selected for, that is, for its evaluative properties.

Here, I propose, is how things went: At some point in evolutionary history, beings happened to pop into existence (as a result of random mutation) for whom there was something 'that it is like' to be them (including feelings of pleasure and pain). These beings started having evaluative thoughts (upon realising the value of these pleasures and pains). Some of them then formed intrinsic desires for the good, and so started pursuing their own pleasures and avoiding their own pains. When further random mutations occurred resulting in beings that experienced pain on being injured, and pleasure on eating nutritious food, these beings did considerably better than any others at surviving and reproducing.

I will not here attempt to defend (C), except to note that it does not entail hedonism of any sort. My own view happens to be the strong one, on which nothing has value except insofar as it contributes to pleasure or pain-avoidance. But this strong view isn't required here. Many non-hedonists are willing to accept that pleasures and pains are the most obviously good and bad things, and even that their existence is a necessary condition of value in the universe. ${ }^{9}$

What can be said in defense of (B)? Perhaps evaluative thought requires contact with things of value in the same way that understanding what red is requires experiences of red. ${ }^{10}$ But a weaker claim will suffice for my purposes here. All that the above argument requires is that the only available way-or perhaps even just the "cheapest" or most efficient way-of early beings coming to possess evaluative concepts was by their encountering things of value.

Note that the story I have given does not explain why phenomenal consciousness occurred as a mutation in the first place. It explains only why, once phenomenal consciousness occurred, it was selected for.

\section{Reconciling Reasons}

\footnotetext{
${ }^{9}$ See Kagan (2009).

${ }^{10}$ For the claim that understanding what red is requires experiences of red, see Jackson (1982).
} 
Normative reasons for action are those reasons we have to do certain things. ${ }^{11}$ There are two main theories of such reasons: subjectivism and objectivism. According to subjectivism, our reasons are provided by our desires. When we have a reason to do something, this is just because our doing it would satisfy some desire of ours (either an actual desire, or one we would have if we were fully informed and vividly imagining all relevant facts). ${ }^{12}$

By contrast, on objectivism, our reasons are provided by the good-either by the goodness of the things that are good or (on buck-passing accounts) by these good things directly. ${ }^{13}$ When we have a reason to do something, this is just because there would be something valuable achieved by doing it.

Both subjectivism and objectivism are attractive in their own ways. Consider subjectivism. It seems there could be cases in which there would be nothing good about someone's doing a certain thing, but where we have to concede that this person has every reason to do the thing and no reason not to. Suppose, for instance, that aliens are thinking of invading Earth, killing us all, and taking our resources. ${ }^{14}$ If these beings care nothing about us, and indeed, let us suppose, are incapable of doing so, then they might, it seems, have every reason to invade and no reason not to, despite the extreme badness of their doing so. ${ }^{15}$

A second reason to like subjectivism is that objectivism faces major difficulties. Objectivism implies that intrinsic desires can themselves be intrinsically reasonable or unreasonable. Many objectivists hold, for example, that even if you don't care about others or their well-being, you should care about these things. ${ }^{16}$ One should care about others and their well-being whatever one is like. While this might sound plausible on its face, it is difficult upon closer inspection to make much sense of it. Intrinsic desires, after all, are simply not in the business of trying to get

\footnotetext{
${ }^{11}$ It is notoriously difficult to characterise the subject matter of reasons for action in an informative but neutral or non-question-begging way. Many have said that a normative reason for action is a consideration that speaks in favour of acting some way. But this doesn't seem terribly informative to me. I propose instead the following characterisation: A person has a reason to do a certain thing just in case it would be in some way fitting or appropriate that she have some motivation to do the thing in question. For more on fittingness approaches in metaethics and value theory, see McHugh and Way (2016), Howard (forthcoming), and Chappell (2012).

${ }^{12}$ See, for example, Sobel (2001), Brandt (1979), Williams (1981), and Schroeder (2007).

${ }^{13}$ See Parfit (2011), Quinn (1993), and Scanlon (1998).

${ }^{14}$ See Harman (1975).

${ }^{15}$ It would not, of course, follow from subjectivism that we should let them invade. We might, given our own cares and concerns, have every reason to resist them. See Williams (1995).

${ }^{16}$ One objectivist, Parfit, writes: "We have instrumental reasons to want something to happen, or to act in some way, when this event or act would have effects that we have some reason to want. As that claim implies, every instrumental reason gets its normative force from some other reason. This other reason may itself be instrumental, getting its force from some third reason. But at the beginning of any such chain of reasons, there must be some fact that gives us a reason to want some possible event as an end, or for its own sake. Such reasons are provided by the intrinsic features that would make this possible event in some way good." Parfit (2011), p. 91.
} 
how the world is right in any way. They are brute existences. It is exceedingly odd, then, to think that they could be fitting or unfitting, appropriate or inappropriate, in any intrinsic sense.

Moreover, what if there were beings who were constitutionally incapable of desiring the things that one ought intrinsically to desire? Recall the aliens above. If they are constitutionally incapable of intrinsically caring about the well-being of humans, in what sense could it be true that they ought so to care? Plausibly, after all, 'ought' implies 'can'.

Consider now objectivism. Why is it attractive? There are, it seems to me, two important motivations for objectivism. First, it is tempting to think that there can be reasons to act only if some things matter. If nothing mattered, then it would not matter what we did, and in this case it is hard to see how any of us could have a reason to do anything. If nothing mattered, then in carrying on our daily lives, thinking we had reasons to act and acting on these supposed reasons, it would seem that we were all making some kind of mistake or operating under a delusion. If objectivism is true, this is easy to explain. By contrast, if subjectivism is true, it is not clear we could explain it. On subjectivism, it should be enough in order for there to be reasons, that there be some beings who care about things and can do something about them.

The second reason objectivism is attractive is that it is tempting to think that there are some things that each of us has a reason to do-say, treat others well, avoid one's own future suffering, and so on. ${ }^{17}$ Objectivism can easily account for this. It is not obvious, however, whether subjectivism can do so. On subjectivism, if someone happened to care nothing about others, then it would seem possible that this person has no reason whatever to treat others well.

Now, to the central claim of this section. If EBF is true, then there is a way to reconcile subjectivism and objectivism. Specifically, we can be subjectivists who get the main benefits of objectivism. How so? Start with the first reason objectivism is attractive-i.e., the apparent dependence of our reasons on some things mattering. If reasons are (as subjectivism says) provided by desires, and (as EBF says) the only thing each of us intrinsically cares about is the good, then it is clearly a necessary condition of anyone's having a reason to do anything that there be some things of value in the world. If nothing mattered, then those who went about their lives thinking they had reasons to act would be in a clear sense mistaken or deluded.

Now consider the second reason objectivism is attractive-i.e., the seeming fact that there are some things that each of us has a reason to do. Why do I have a reason to avoid my own future suffering even if I am indifferent to my own future self's interests? If EBF is true, we can say it is because such suffering would be a bad thing, and (like every other desiring creature) I am concerned about what would be bad. Why do I have a reason to treat others well, whether or not I care about these particular individuals? It is because, while I might not care about others at all, I necessarily care about the good, and the well-being of others is something that is good. Just as objectivists have been at pains to emphasise, my reason to treat others well is not (as subjectivists tend to say) that I happen to care about these particular

\footnotetext{
${ }^{17}$ See Parfit (2011).
} 
people. My reason is that it is good that they do well. It's just that this is a reason for me only in combination with my necessary desire for the good. ${ }^{18} 19$

\section{Objections}

Despite its significant explanatory power, some readers will find EBF hard to accept. Some will object that there are clearly times when we think something would be good (or even best) without wanting it at all. For example, I might know it would be best to go to the dentist today, while having no desire whatever to do so.

But we must be careful not to confuse a desire for something with mere attraction to, or feeling like, it. To be attracted to or feel like something is a matter of vividly anticipating some pleasure or pain-relief from it, something that does not imply a desire for it. This is relevant because it is entirely possible to think something would be good in some way without being attracted to or feeling like it at all, and this fact might be what is confusing some critics here. Take the case of the dentist. In this familiar sort of case, what seems to be going on is that one thinks it would be good to visit the dentist, but does not feel like going at all (since one does not-at least, not in the case of a routine check-up-vividly anticipate any pleasure or painrelief from so doing). It does not follow that one does not want to go. One might well have some desire to go, in the relevant sense. ${ }^{20}$

Others will object to EBF that there are clearly times when we want something without thinking it good at all. For example, one might desire one of the following things without thinking it good in the slightest:

To splash about in the bath like a fish. ${ }^{21}$

To smash icicles. ${ }^{22}$

To steal pears from a nearby orchard in order to discard them. ${ }^{23}$

That a high speed car chase one is watching on TV end in a spectacular crash.

To wash one's hands repeatedly.

To put all the items on one's desk in a rigid, regular order. ${ }^{24}$

That one's friend fail in some pursuit.

To smash one's opponent in the face with one's squash racquet. ${ }^{25}$

To drown one's bawling baby in the bath water. ${ }^{26}$

\footnotetext{
${ }^{18}$ My reconciling strategy here has similarities to the constitutivism of Korsgaard (1996) and Velleman (2005).

${ }^{19}$ I acknowledge that my reconciling strategy will not satisfy some objectivists, who will want to maintain that not only do each of us in fact have a reason to treat others well, this would remain true whatever people desired. For a nice articulation of this worry, see Schroeder (2007), p. 107.

${ }^{20}$ Of course, one might feel like going to the dentist if one is suffering pain from toothache, and anticipates that the dentist will be able to quickly remedy this.

${ }^{21}$ See Raz (2010).

${ }^{22}$ See Sussman (2009).

${ }^{23}$ See Sussman (2009).

${ }^{24}$ See Stocker (2004).

${ }^{25}$ See Watson (1982).

${ }^{26}$ See Watson (1982).
} 
However, it is again vital to distinguish between desiring something and merely feeling like it. There are indeed times when one feels like something (i.e., vividly anticipates some pleasure or pain-relief from it) without thinking it would be good at all. This might be going on in some of the above sorts of cases. It does not follow, however, that one can genuinely want something, in the relevant sense, without thinking that it would be good in some way.

It might be objected to what l've just said that in some of the above cases, it is clear that the relevant individuals do not merely feel like the things in question, but actually want them as well, since they might actually perform the associated actions. Some people smash their opponents, drown their babies, wash their hands repeatedly, and so on. But it is not plausible, this objection goes, that in all these cases the individuals concerned think these actions would be best. On the contrary, all normal individuals know, at all times, that such actions are not best.

But this seems to me far too optimistic about our cognitive capacities. We humans are finite beings, who can hold in our heads only so much at a single time. People who are extremely stressed or suffering greatly might simply run out of mental space at certain times for continuing to appreciate the value of things outside of themselves and their own immediate feelings. The stress or suffering felt by a frustrated squash player or young mother who is struggling to cope with her new life as a parent might, if only for a brief moment, become so overwhelming or dominant in these people's psychologies that it literally crowds out, for the duration of that moment, their appreciation of the true nature or extent of the disvalue of their opponent's being injured or their baby's being drowned. This moment might be brief, but long enough to act in.

It might next be objected that EBF lacks the resources to account for some phenomena we all know well: temptation and weakness of will. It is a familiar fact, it might be said, that it can be hard to get oneself to do what one thinks best, and sometimes one fails. EBF is inconsistent with this plain fact. If EBF were true, it should be neither easy nor hard to do what one thinks best-judging an action best and deciding to do it should go hand in hand, so to speak.

But I think EBF actually provides a very appealing account of what is going on in temptation and weakness of will. We can explain these things on the model of concentration. Consider what it is like to try to hold on to an idea in your head while you are sleepy, or remember what you were planning to say while waiting for a gap to come up in conversation, or keep in mind a certain number (a phone number, perhaps) while your mean friends are trying to make you forget it by reciting numbers at random, or focus on your work while catchy music is playing in the background or people are chatting loudly on their cell-phones, etc. It can be hard. It is in just the same way, I want to suggest, that exercising willpower can be hard. Moments of temptation are moments when we are aware that, owing to our experience or vivid anticipation of certain intense pleasures, our judgment of what would be best is changing, and we are going to have to exercise real mental effort if we are to keep hold of our existing judgment. Willpower, then, can be understood as a species of concentration. It is concentration on the good.

An example might help to explain what I mean here. Suppose Alex, who is on a diet, is offered some chocolate cake. He thinks it would be best to refrain, but is 
sorely tempted. His temptation here, I am suggesting, consists in his awareness that his anticipation of pleasure from the cake is starting to change his belief about what would be best that he do. He sees that he is starting to form the false belief that it would be best to break his diet on this particular occasion and eat the cake. The more he thinks about eating the cake and the associated pleasure, the larger the value of this pleasure looms in his consciousness, and the less he is able to focus on the value of sticking with his diet on this occasion. If Alex exercises willpower to resist this temptation and succeeds in resisting it, this is just his succeeding in concentrating on the good of sticking with his diet long enough to outlast the threatened change to his evaluative belief. ${ }^{27}$

It might next be objected that EBF cannot account for the existence of the reactive attitudes-our feelings of indignation, resentment, guilt, etc. If we always decide to do what we think best, what could possibly explain these feelings? Furthermore, if we always decide to do what we think best, how could it ever be appropriate or fitting for us to feel them?

EBF, however, I believe, has a good way of accounting for the existence of these feelings, as well as their appropriateness on certain occasions. Why do we feel these things? Not out of an awareness of somebody's acting contrary to her own judgment of what would be best, but rather from an awareness that somebody has a tendency to forget about or lose sight of the well-being of others or its value. When are such feelings fitting or appropriate? Just when they are felt in response to somebody's in fact possessing this regrettable tendency.

$E B F$, indeed, explains why these feelings have the particular phenomenal character they do. Why do we feel just these 'hot' or angry emotions toward those who have a tendency to lose sight of the well-being of others or its value, rather than some other sort of feelings lacking any such 'hotness'? If EBF is true, we can say it is because of the usefulness of such feelings in helping ourselves and others to better concentrate on, or keep in mind, the well-being of other people.

Consider the following analogy with sport. It is common for athletes to feel angry with themselves for, say, missing an easy shot or choosing the wrong strategy at a crucial moment. These angry or 'hot' feelings, it seems, can be in a certain way fitting or appropriate at times. Why is it these particular 'hot' feelings that are the fitting or appropriate response to such errors? It seems to have to do with the usefulness of such feelings in helping athletes to concentrate better in the future. On the next occasion they face a shot or choice of this kind, they will be unconsciously aware that if they lose concentration again, they will have to contend with their own angry attitudes (something that each of us naturally wants to avoid).

A similar thing is going on, I want to suggest, in the moral case. Feeling angry with someone (either oneself or another) for losing sight of other people's wellbeing or its value can be the fitting or appropriate thing to feel at certain times because of its usefulness in helping one to better keep in mind or concentrate on the well-being of others. When one realises that one has lost sight of such things and

\footnotetext{
${ }^{27}$ I do not claim to have proven here that this is the right account of temptation and willpower. My point is the more minimal one that there is a promising explanation of this phenomena available to an advocate of EBF.
} 
feels such a corresponding sting, one is thereby made less likely to lose concentration on other people's well-being or its value in the future.

This account also explains why such attitudes can be appropriately felt only toward normal adult humans. Babies and non-human animals cannot understand other beings' well-being or its value in the sort of way necessary to possess the relevant tendency to lose sight of these things. As for human adults who act badly only because they are, say, hypnotised, coerced, mentally ill, etc., while they (unlike babies and non-human animals) do possess the ability to understand other beings' well-being and its value, their actions on these occasions are not the result of the sort of tendency to lose sight of these things that I have been referring to. ${ }^{28}$

I want to consider one final objection to EBF. EBF, it might be said, is inconsistent with the existence of morally bad people. If we always decided to do what we thought best, then we would all be moral saints or morally unimpeachable, something that is clearly not the case.

But there is a way in which, on EBF, there can be morally bad people. This is because, even if we all necessarily decide to do what we think best, some of us possess the above-mentioned regrettable tendency to lose sight of, or fail to think about, the well-being of others or its value. This tendency seems the very heart of selfishness, a paradigm moral failing.

Perhaps EBF is incompatible with a certain kind of morally bad personnamely, the sort of person who deserves to suffer for her bad actions or character (i.e., whose suffering would be intrinsically good due to who she is or what she has done). Such a person might indeed have to be capable of acting clear-eyedly against her own judgment of what would be best. But this incompatibility, I would suggest, is not a drawback, but rather an advantage of EBF. It seems very doubtful that anyone could deserve to suffer in the way just described. Nobody's suffering in and of itself makes the world go better. EBF nicely explains why this is so.

\section{Conclusion and Implications}

In this chapter, I have provided a preliminary defense of EBF, the view that each of us has just one intrinsic desire, a desire for the good, and that every other desire we have is the combination of this intrinsic desire and some belief that a certain thing would be good in some way. EBF, I argued, is highly explanatory and has promising answers available to it to the most serious objections it faces.

I want to finish by pointing out two important implications of EBF. Suppose EBF is true. What follows? First, we needn't worry that we think some things matter only because we happen to want or care about things and are projecting these desires onto the external world. If EBF is true, there cannot be any desires without evaluative beliefs first.

Second, having ruled out the possibility that our evaluative thoughts are due merely to our wanting things, it becomes much more plausible to think that some things really do matter or have value (i.e., that some sort of value realism is true). This is because, having ruled out the aforementioned possibility, it becomes much more likely that our evaluative thoughts are due to our encountering real value. Why

\footnotetext{
${ }^{28}$ I am influenced here by Smart (1961) and Schlick (1939).
} 
do we think that there are some things that matter or have value? It is because there are such things and we have come to recognise this.

\section{References}

Brandt, R. (1979). A Theory of the Good and the Right. Oxford: Clarendon Press. Chappell (2012). Fittingness: the sole normative primitive. Philosophical Quarterly, 62 (249): 684-704.

Goldstein, I. (1980). Why people prefer pleasure to pain. Philosophy 55: 349-362. Gregory, A. (forthcoming) Might desires be beliefs about normative reasons? In

Deonna, J. and Lauria, F. (Eds.) The Nature of Desire. Oxford University Press. Harman, G. (1975). Moral relativism defended. Philosophical Review 84 (1):3-22. Howard, C. (forthcoming). The fundamentality of fit. Oxford Studies in Metaethics. Humberstone, L. (1987). Wanting as believing. In Canadian Journal of Philosophy 17: 49-62.

Jackson, F. (1982). Epiphenomenal qualia. Philosophical Quarterly 32: 127-136.

Kagan, S. (2009). Well-being as enjoying the good. Philosophical Perspectives 23 (1): 253-272.

Korsgaard, C. (1996). The Sources of Normativity. Cambridge, UK: Cambridge University Press.

McHugh, C. and Way, J. (2016) Fittingness first. Ethics 126 (3)

McNaughton, D. (1988). Moral Vision: An Introduction to Ethics. Blackwell.

Oddie, G. (2005). Value, Reality, and Desire. Oxford.

Parfit, D. (2011). On What Matters. Oxford: Oxford University Press.

Quinn, W. (1993). Putting rationality in its place. In Quinn, W., \& Foot, P. Morality and Action. Cambridge University Press, 228-255.

Raz, J. (2010). On the guise of the good. In Tenenbaum, ed., Desire, Practical Reason, and the Good . Oxford University Press US.

Scanlon, T. M. (1998) What We Owe to Each Other. Cambridge, MA: Belknap Press. Schlick, M. (1939.) Problems of Ethics, tr. by David Rynin. New York: Prentice-Hall. Schroeder, M. (2007). Slaves of the Passions. Oxford: Oxford University Press.

Schroeder, T. (2004). Three Faces of Desire. New York: Oxford University Press.

Smart, J. J. C. (1961). Free-will, praise, and blame. Mind 70: 291-306.

Smith, M. (1994). The Moral Problem. Oxford University Press.

Sobel, D. (2001). Subjective accounts of reasons for action. Ethics 111(3): 461-492.

Stampe, D. (1987). The authority of desire. The Philosophical Review 96: 335-81.

Stocker, M. (2004). Raz on the intelligibility of bad acts, in R. J. Wallace, P. Pettit, S. Scheffler, M. Smith, eds., Reason and Value: Themes from the Moral Philosophy of Joseph Raz. Oxford: Oxford University Press, 303-32.

Sussman, D. (2009). For badness sake. Journal of Philosophy, 106: 613-628.

Tenenbaum, S. (2007). Appearances of the Good: An Essay on the Nature of Practical Reason. New York: Cambridge University Press.

Velleman, J. D. (2005). Self to Self. New York: Cambridge University Press. Watson, G. (1982). Free agency. In Free will. Oxford: Oxford University Press. Williams, B. (1995). Internal reasons and the obscurity of blame. Reprinted in his Making Sense of Humanity. Cambridge. Cambridge University Press. 